\title{
AIR TRANSPORT PILOTS' INFORMATION PRIORITIES FOR SURFACE MOVING MAPS
}

\author{
Michelle Yeh and Divya Chandra \\ US DOT Volpe Center \\ Cambridge, MA
}

\begin{abstract}
The use of a surface map display for operations on or near the airport surface (taxi out, takeoff, final approach and landing, taxi in) is expected to enhance safety. There is a lack of research, however, detailing how the airport surface should be depicted to air transport pilots during taxi operations. In order to address this question, an information analysis was conducted in which air transport pilots provided self-reported ratings of need for display elements found on current airport diagrams or made available on prototype surface map displays for operations on or near the airport surface. The ratings highlighted the value of presenting runway location and traffic information across all operational phases and showed the changing utility for display elements across different phases of operations. Comparison of the air transport pilot ratings with general aviation pilot ratings showed general agreement as to which display elements were of high value. Differences between the two groups were largely attributable to differences in the nature of operations.
\end{abstract}

\section{INTRODUCTION}

The Federal Aviation Administration (FAA) Safe Flight 21 program office is examining the use of electronic surface map displays to enhance safety and reduce incidents on or near the airport surface. The airport is a complex and highly dynamic environment; unfamiliarity with the airport layout, deficiencies in airport surface markings (e.g., poor signage), or non-optimal weather or lighting conditions increases the difficulty of determining ownship position as well as the position of other vehicles and could lead to disorientation (Andre, 1995). In fact, an analysis of accident statistics, which included near misses, revealed that the airport surface had the highest potential for catastrophe, leading the then FAA Administrator, Jane Garvey, to note that "taxiing on the airport surface is the most hazardous phase of flight" (Gerold, 2001).

As shown in Figure 1, the surface map is presented on an electronic display, constructed from a database that contains positional data describing the location of runways, taxiways, non-movement areas, ramp areas, and buildings. Data from the Global Positioning Satellites (GPS) combined with other surveillance technologies, e.g., Automated Dependent Surveillance-Broadcast (ADS-B), provide a means to display real-time ownship position and the position of other aircraft and surface vehicles. It is expected that the presentation of this information will aid in the visual acquisition of surface elements (e.g., runways and taxiways) and increase pilots' awareness of the airport layout (Batson, Harris, and Hunt, 1994; Battiste, Downs, and McCann, 1996). Additionally, it is anticipated that this display of vehicle information will increase pilots' awareness of traffic on or near the runways and allow pilots to infer traffic intent with respect to surface movements (RTCA, 2002a,b).

The determination of which display elements to show and when requires an understanding of the value pilots place on the presentation of different display elements throughout different phases of operations. Schvaneveldt, Beringer, and Lamonica (2001) conducted such an analysis to determine information priorities during flight. In their study, a taxonomy of display elements for seven flight phases and two planning phases was created by analyzing the information used in normal flight operations. Items included in their questionnaire represented both broad categories of information (e.g., general

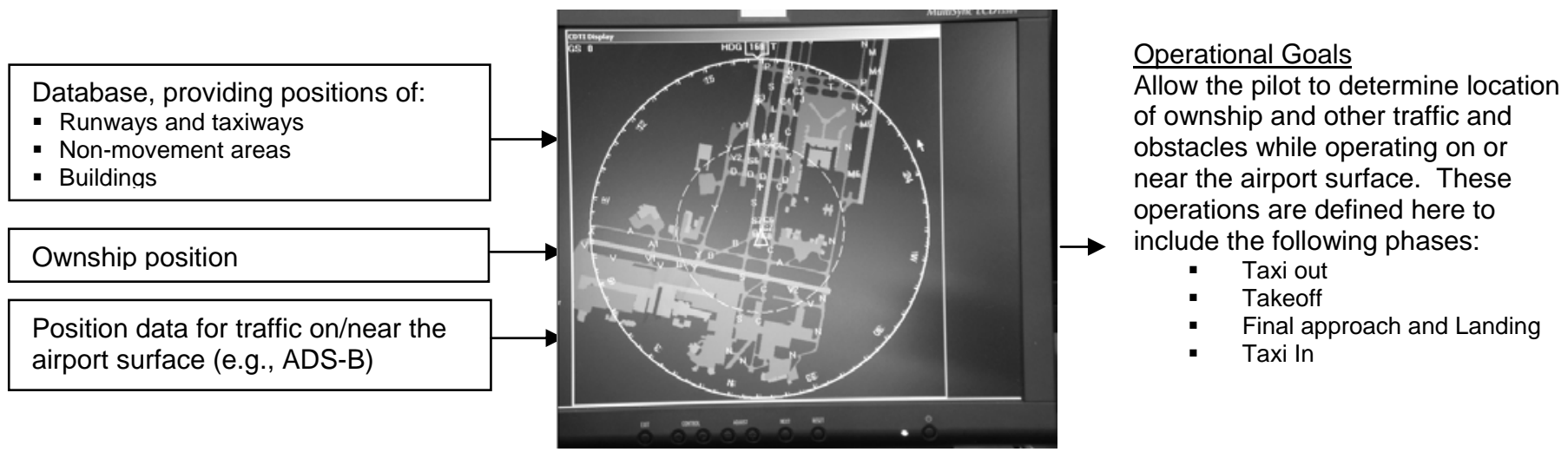

Figure 1. Surface map display system. The prototype display shown here is developed by the William J. Hughes FAA Technical Center. 
weather) and very specific items (e.g., altitude, distance). The analysis presented an overall ranking of information priorities across flight phases, and revealed a shifting of priorities across the phases of flight as well as between flight and planning phases.

There is a lack of research, however, detailing the display elements that are useful in describing the airport surface (FAA, 2001). The design of surface map prototypes has so far been based on assumptions regarding the value of various airport map attributes. Using a technique similar to that of Schvaneveldt, et al., Yeh and Chandra (2003) conducted a study to determine a set of display elements useful to general aviation (GA) operations. While Schvaneveldt, et al. focused on flight phases, Yeh and Chandra placed emphasis on operations on or near the airport (i.e., up to 1000 feet above ground level). GA pilots were presented with a list of display elements, and asked to rate the need for each display element for different operations on or near the airport surface. The questionnaire included airport features found on current taxi charts (e.g., runway and taxiway information) or that have been made available with ADS-B technology (e.g., the location of air and surface vehicles). Only a handful of items were found to be highly useful for all phases of operations. In fact, the results reflected the changing value of display elements throughout the different operational phases, similar to those reported by Schvaneveldt, et al.

The study conducted by Yeh and Chandra focused on GA operations, however, and does not address the issue of how to organize display elements for air transport operations. This was the objective of the current experiment. Our interest

Runway Information
Runways
Runway centerlines
Runway displaced thresholds
Runway edges
Runway elevation
Runway end elevation
Runway heading
Runway hold short lines
Runway labels
Runway landing length
Runway length
Runway lighting
Runway markings
Runway shoulder
Runway slope
Runway stopways
Runway surface information
Runway weight bearing capacity
Runway width
Taxiway Information
Taxiways
Taxiway bearing strength (when
less than associated runway)
Taxiway centerlines
Taxiway edges or boundaries
Hold short lines
Taxiway labels
Taxiway width
ILS critical areas
ILS hold lines
Runing

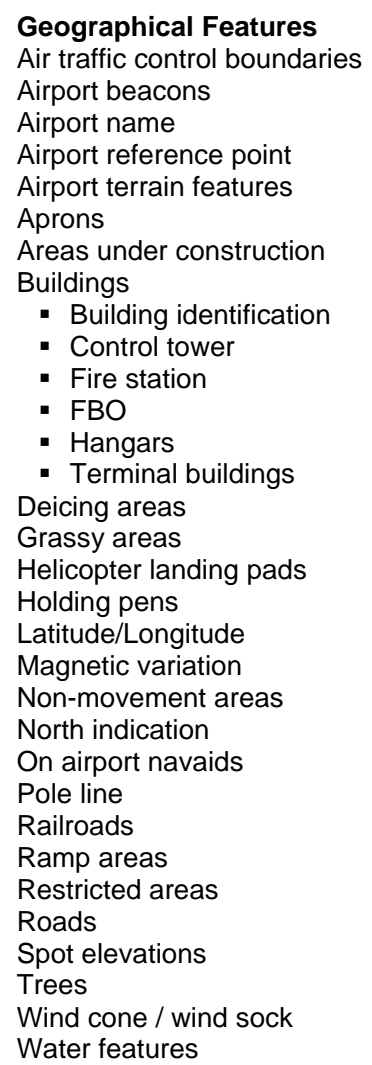

here was to determine how display elements may be organized for air transport operations, so that the pilot is presented with the appropriate display elements at the appropriate time. Additionally, it was of interest to compare the results of the air transport analysis to those of the GA analysis, discussed above.

\section{METHODS AND PROCEDURE}

\section{Participants}

Nineteen pilots from a commercial airline participated in the study. Seventeen were 757/767 pilots and two were 777 pilots. The pilots averaged 7391 flight hours.

\section{Questionnaire}

Pilots were presented with a set of forms, including a consent form, a demographics questionnaire, forms listing display elements for four phases of operations on or near the airport surface (taxi out, takeoff, final approach and landing, and taxi in), a glossary of terms, and an airport diagram for reference. Pilots were informed that the goal of the surface map application was to support their knowledge of ownship position, traffic location, and runway occupancy.

Additionally, pilots were told that the surface map was intended to supplement the information that was available on a paper chart and out-the-window.

The display elements consisted of items that are currently available on paper charts or that will be available with ADS-B technology. A list is presented in Table 1.

\section{Ownship Information \\ Ownship \\ Ownship heading \\ Ownship ground speed \\ Lubber line}

Traffic Information

Indication of traffic status (in

air/on ground)

- Traffic in air

- Traffic call sign (traffic in air)

- Traffic on the ground

- Traffic call sign (traffic on ground)

Traffic altitude

- Absolute

- Relative

Traffic location

Selected target indicator

- Selected target speed

- Selected traffic identification

- Selected target aircraft class

- Selected target distance

Predictor

\author{
Obstacles \\ Condition of surface areas (other \\ than runways) \\ Obstructions
}

\section{Status Indications}

Compass rose/arc

Range information

Full range ring

Half-range ring

Map scale

Taxi Information

Ground track vector

Gate numbers

Table 1. Display elements considered. 
The elements can be categorized into eight classes: runway information, taxiway information, ownship information, traffic information, status indications, geographical features, and obstructions. For each of these display elements, pilots were asked to rate how much they needed it for each phase of operations on or near the airport surface, using the following scale:

$\begin{array}{ll}\mathbf{5} & \text { Very high need } \\ \mathbf{4} & \text { High need } \\ \mathbf{3} & \text { Moderate need } \\ \mathbf{2} & \text { Low need } \\ \mathbf{1} & \text { Very low need } \\ \mathbf{0} & \text { No rating }\end{array}$

The phases of operations were defined as follows:

o taxi out: taxi from the gate (or hangar) to the runway

o takeoff: enter the runway to wheels off the ground

o final approach and landing: established on the final approach to landing and turnoff

o taxi in: taxi from the runway to the gate (or hangar)

\section{RESULTS}

Mean ratings were calculated for each display element within each of the four phases of operations. A single factor analysis of Variance (ANOVA), conducted on the data for each phase of operations, revealed significant differences in the display element ratings [taxi out, $F(87,1516)=10.22$, p $<0.01$; takeoff, $F(87,1489)=6.43$, p $<0.01$; final approach and landing, $F(87,1515)=6.90$, p $<0.01$; taxi in, $F(87,1504)$ $=8.65, \mathrm{p}<0.01)]$. We were interested in determining if the pilot ratings could be used to identify a set of display elements to depict for each operational phase. As with the GA information analysis, we attempted to determine if a set of minimum display elements could be identified based on the similarities in the need ratings using a Newman-Keuls analysis for each operational phase. The sample size here, however, was not sufficient for any meaningful results. Consequently, the display elements were prioritized based on the defined rating scale, shown above, a method similar to that used by Schvaneveldt, et al. The results will focus on the display elements considered to be high value, those with a rating of 4.0 or higher, and display elements of low value, those with a rating of 2.0 or lower.

\section{Highly Rated Display Elements}

The display elements that were considered to be of high value are presented in Table 2.

The ratings highlight the changing value for display elements depending upon the operational phase. Only two display elements were given a rating of 4.0 or higher across all operational phases: the depiction of runway-pavement location and traffic location. Items related to runways, e.g., the depiction of runway-pavement and runway markings (centerlines, displaced thresholds, and edges), were rated higher during taxi out, takeoff, and final approach and landing than during taxi in. In fact, paired comparisons revealed that the mean rating for the depiction of runway-pavement was significantly higher during taxi out (4.89) and final approach and landing phases (4.84) than it was during taxi in (4.05) $[t(36)=3.42, \mathrm{p}<0.01$ and $t(36)=3.15, \mathrm{p}<0.01$, respectively]. This finding is inconsistent with the actual importance of runway pavement during taxi in, particularly if pilots are given complex clearances that require them to cross runways on their way to the gate or parking area.

Additionally, the ratings reveal a subset of display elements important specifically to taxi phases (taxi in, taxi out). Here, pilots reported that airport information relevant to their surface movement, i.e., about where they could move (taxiways, taxiway labels and taxiway edges), where they could not (areas under construction, ILS critical areas, restricted areas), who might be in the way (traffic on the ground), and where to wait for instructions (ILS hold lines, hold short lines) were of high value. For operations near the

\begin{tabular}{|c|c|c|c|c|c|c|c|c|c|c|}
\hline \multicolumn{3}{|c|}{ Taxi Out } & \multicolumn{3}{|c|}{ Takeoff } & \multicolumn{3}{|c|}{ Final Approach and Landing } & \multicolumn{2}{|l|}{ Taxi In } \\
\hline 1 & Runways & 4.89 & 1 & Runways & 4.53 & 1 & Runways & 4.84 & 1 Taxiways & 4.68 \\
\hline 2 & Hold short lines & 4.84 & 2 & Traffic in air & 4.37 & 2 & Runway displaced thr & esholds & 2 Hold short lines & 4.68 \\
\hline 3 & Runway hold short lines & 4.79 & 3 & Runway centerlines & 4.32 & & & 4.79 & 3 Taxiway labels & 4.47 \\
\hline 4 & Areas under construction & 4.68 & 4 & Traffic location & 4.26 & 3 & Runway centerlines & 4.58 & 4 Gate numbers & 4.32 \\
\hline 5 & Taxiways & 4.67 & 5 & \multicolumn{2}{|c|}{ Indication of traffic status (in } & 4 & Traffic location & 4.26 & 5 Runway hold short lines & 4.32 \\
\hline \multirow[t]{2}{*}{6} & \multicolumn{2}{|l|}{ Runway displaced } & & \multicolumn{2}{|c|}{ air/on ground) } & 5 & Runway edges & 4.26 & 6 Traffic location & 4.32 \\
\hline & thresholds & 4.53 & & & 4.24 & 6 & Runway landing length & 4.26 & 7 Taxiway centerlines & 4.32 \\
\hline 7 & Runway edges & 4.42 & 6 & Traffic altitude & 4.13 & 7 & \multicolumn{2}{|c|}{ Indication of traffic status (in } & \multicolumn{2}{|c|}{8 Taxiway edges or boundaries } \\
\hline 8 & Taxiway labels & 4.37 & 7 & Runway edges & 4.11 & & air/on ground) & 4.24 & & 4.26 \\
\hline 9 & Ownship & 4.32 & 8 & \multirow{2}{*}{\multicolumn{2}{|c|}{$\begin{array}{l}\text { Runway hold short lines } 4.06 \\
\text { Runway displaced thresholds }\end{array}$}} & 8 & Runway lighting & 4.11 & 9 Ramp areas & 4.26 \\
\hline 10 & Traffic location & 4.26 & 9 & & & & Airport terrain features & 4.05 & \multicolumn{2}{|c|}{10 Areas under construction 4.21} \\
\hline 11 & Traffic on the ground & 4.21 & & & 4.05 & & Ownship & 4.05 & 11Traffic on the ground & 4.21 \\
\hline 12 & ILS critical areas & 4.21 & & & & & Obstructions & 4.00 & 12 Ownship & 4.21 \\
\hline 13 & ILS hold lines & 4.21 & & & & & & & 13Restricted areas & 4.11 \\
\hline 14 & Restricted areas & 4.11 & & & & & & & 14Runways & 4.05 \\
\hline 15 & \multicolumn{2}{|c|}{5 Taxiway edges or boundaries } & & & & & & & 15ILS hold lines & 4.05 \\
\hline & & 4.11 & & & & & & & 16 Obstructions & 4.00 \\
\hline 16 & Runway labels & 4.11 & & & & & & & & \\
\hline 17 & Indication of traffic status & & & & & & & & & \\
\hline & air/on ground) & 4.11 & & & & & & & & \\
\hline 18 & Runway centerlines & 4.00 & & & & & & & & \\
\hline
\end{tabular}

Table 2. Highly rated display elements. Items in bold are not currently depicted or marked on prototype surface map displays. (Item rank is given on the left side within each column. Mean rating is given on the right.) 


\begin{tabular}{|c|c|c|c|c|c|c|c|c|c|}
\hline \multicolumn{2}{|l|}{ Taxi Out } & \multicolumn{3}{|c|}{ Takeoff } & \multicolumn{2}{|c|}{ Final Approach and Landing } & \multicolumn{3}{|c|}{ Taxi In } \\
\hline 88 Airport beacons & 1.47 & & Railroads & 1.47 & 88 Magnetic variation & 1.59 & 88 & Railroads & 1.53 \\
\hline 87 Railroads & 1.54 & 8 & FBO & 1.63 & 87 Railroads & 1.60 & 88 & Magnetic variation & 1.53 \\
\hline 86 Trees & 1.69 & 8 & Airport beacons & 1.67 & 86 Latitude/Longitude & 1.67 & 86 & Water features & 1.65 \\
\hline 85 Magnetic variation & 1.73 & 85 & Building identification & 1.68 & 85 Deicing areas & 1.81 & 85 & Trees & 1.67 \\
\hline 84 Helicopter landing pads & 1.80 & 8 & Magnetic variation & 1.71 & 85 FBO & 1.81 & 84 & Wind cone / wind sock & 1.71 \\
\hline 83 Water features & 1.88 & 8 & Hangars & 1.74 & 83 Hangars & 1.88 & 83 & Pole line & 1.75 \\
\hline & & 8 & Ramp areas & 1.75 & 82 Building identification & 1.94 & 82 & Runway elevation & 1.82 \\
\hline & & 8 & Roads & 1.75 & 82 Pole line & 1.94 & 82 & Runway slope & 1.82 \\
\hline & & 80 & Non-movement areas & 1.80 & 80 Helicopter landing pads & 2.00 & 80 & Airport beacons & 1.83 \\
\hline & & 79 & Spot elevations & 1.88 & & & 80 & Spot elevations & 1.83 \\
\hline & & $7 \varepsilon$ & Airport reference point & 1.89 & & & 78 & Runway end elevation & 1.88 \\
\hline & & $7 \varepsilon$ & Trees & 1.89 & & & 77 & Helicopter landing pads & 1.94 \\
\hline & & & Helicopter landing pads & 1.93 & & & 76 & Airport reference point & 1.95 \\
\hline & & 75 & Water features & 1.94 & & & 75 & Latitude/Longitude & 2.00 \\
\hline & & 75 & Holding pens & 1.94 & & & & & \\
\hline & & 73 & Gate numbers & 2.00 & & & & & \\
\hline & & & Latitude/Longitude & 2.00 & & & & & \\
\hline & & 7. & Pole line & 2.00 & & & & & \\
\hline
\end{tabular}

Table 3. Low rated items. Item rank out of a total of 88 elements is given on the left within each column. Mean rating is given on the right.

surface (i.e., takeoff and final approach and landing), pilots found detailed information regarding the airport layout (airport terrain features and runway markings) as well as the positions of proximate traffic in the air valuable.

A comparison of the display elements that received the highest ratings to those elements depicted on prototype displays identified some additional display elements which would add value if depicted. The prototype displays used for this comparison were demonstrated at a Safe Flight 21 evaluation in Memphis in May 2002. The surface maps already depicted ownship and traffic positions, runways, runway labels, taxiways, taxiway labels, non-movement areas, and buildings. Items that received high ratings by pilots that were not depicted on surface map displays are presented in bold in Table 2. For taxi phases, pilot ratings highlighted the value for ILS information (hold lines and location information of ILS critical areas) and restricted areas. For phases near the surface, display elements that would add value included runway displaced thresholds and obstructions. It is important to note that some of these display elements, e.g., runway landing length, may be found on current airport diagrams but may still need to be incorporated into airport databases.

\section{Low-Rated Display Elements}

The ratings were also examined to determine what display elements pilots considered to be of little value, i.e., those display elements receiving a mean rating of 2.0 or lower. These items are presented in Table 3 in order of lowest need. The ratings identified three display elements that received low ratings through all four operational phases: railroads, magnetic variation, and helicopter landing pads. Additionally, subsets of display elements could be determined based on similarities in operational phases, i.e., on the ground versus near the ground. For ground operations, the ratings show the low value for geographical elements such as airport beacons, trees, and water features. For operations near the airport surface, low rated items consisted of display elements regarding buildings.

\section{Comparison with GA Pilots}

The ratings from the air transport pilots may be compared to the GA ratings to determine the degree of similarity between the two groups. For the purposes of this analysis, the display elements that received a rating of 4.0 or higher for both populations were compared. The results showed approximately $60 \%$ agreement between air transport pilots and GA pilots regarding which display elements were high need. The similarities in high need display elements were greater for taxi phases, in which approximately $68 \%$ of the display elements were in common, than for phases near the surface ( $50 \%$ of the display elements in common). The comparison showed three similarities between air transport and GA ratings: (1) high value for traffic location information and other data about traffic, available with the introduction of ADS-B, throughout all four operational phases, (2) high value for information regarding taxiways and airport geography for taxi operations on the surface, and (3) a drop in ratings for runway information during taxi in relative to the other three phases.

In general, the differences in high need items were largely attributable to the differences in the types of operations. For example, air transport pilots rated the depiction of ownship position higher than GA pilots for three of the four operational phases. This result may be attributable to differences in the complexity of the airports to which the two pilot populations are accustomed. Typically, air transport operations are conducted at larger, more complex airports than those used by GA pilots. As a result, a constant indication of aircraft location with respect to the airport surface could be especially valuable.

\section{DISCUSSION}

The goal of this research was to identify the value air transport pilots place on various display elements for different operations on or near the airport surface. The results showed that only a handful of elements were rated useful for all operations. These elements provided information regarding 
the location of runways and the position of other vehicles and aircraft. More importantly, the results demonstrate the changing value of display elements for operations on or near the airport surface, similar to that reported by Schvaneveldt, et al. (2001) for flight phases.

Our results were recently presented to a group of subject matter experts from the Society of Automotive Engineers (SAE) G-10 Aeronautical Charting sub-committee. This group is drafting an Aerospace Recommended Practice (ARP) document to recommend priorities for display elements on electronic database-driven charts. While the scope of the display elements and the operational phases considered by the SAE group was considerably greater than those examined here, there was some overlap, and a preliminary analysis was conducted to assess the level of agreement between our air transport ratings and the draft ARP priorities for surface operations. The results of the analysis showed general agreement in the pilot ratings, but highlighted the fact that our questionnaire did not consider the situational context for different display elements. For example, pilots were not asked to consider the need for display elements for non-normal operations or atypical airfields. Hence, it is important to note that low ratings for an item may not indicate low need for the item at all times but rather, they may simply suggest that the item is used infrequently, may be non critical, or have limited utility in dynamic situations.

The results presented here provide a starting point in examining display element priorities. The results suggest the need for more data from air transport pilots. First, the data collected from 19 pilots was not sufficient for rigorous statistical analysis, despite the fact that the pilot population was fairly homogenous. All 19 pilots worked for the same commercial airline and 17 of the 19 pilots flew the same type of aircraft. Second, the information analysis was focused on pilot self-reports and still need to be validated through simulation, as there is evidence that pilots do not always perform best with what they say they prefer (Andre and Wickens, 1995). Nevertheless, the results provide some insight into the value of display elements for air transport operations and are of interest to designers of surface map displays.

The pilot is inundated with information about operations on the airport surface. Sources range from paper charts to that shown on flight deck displays to new surveillance capabilities such as ADS-B. The goal of the designer is to transform all the information available into a usable form. The changing value of display elements highlights the need for user-configurable displays and/or intelligent displays that provide pilots with the most appropriate elements depending on the current operation. The results reported here contribute to an understanding of what information is needed for surface operations.

\section{ACKNOWLEDGEMENTS}

This study was initiated by the Safe Flight 21 Program office. Portions of this work are supported by the Office of the Chief Scientist for Human Factors of the Federal Aviation Administration, headed by Mark Rodgers. We would like to thank FAA Program Managers, Marc Buntin and Tom McCloy, and SF21 Human Factors Application Manager, Michele Heiney, all of whom actively contributed to the success of this project. We would also like to thank Vern Battiste, Randy Bone, Mike McAnulty, and Eric Nadler for their insight and guidance in designing the questionnaire and all the pilots who participated in this study.

The views expressed are those of the authors and do not reflect the views of the Volpe National Transportation Systems Center, the Research and Special Programs Administration, or the United States Department of Transportation.

\section{REFERENCES}

Andre, A.D. (1995). Information requirements for lowvisibility taxi operations: What pilots say. In R.S. Jensen and L.A. Rakovan (Eds.), Proceedings of the Eighth International Symposium on Aviation Psychology (pp. 484-488). Columbus: Ohio State University.

Andre, A.D. and Wickens, C.D. (1995). When users want what's not best for them. Ergonomics in Design (pp. 1014). Human Factors and Ergonomics Society: Santa Monica, CA.

Batson, V., Harris, R., and Hunt, P. (1994). Navigating the Airport Surface: Electronic vs. Paper Maps. Proceedings of the 13th Digital Avionics System Conference. AIAA/IEEE.

Battiste, V., Downs, M., and McCann, R.S. (1996). Advanced taxi map display design for low-visibility operations. Proceedings of the Human Factors and Ergonomics Society 40 ${ }^{\text {th }}$ Annual Meeting (pp. 997-1001). Human Factors and Ergonomics Society: Santa Monica, CA.

FAA (2001). Operational Evaluation-2 Final Report. Washington DC.

Gerold, A. (2001). Runway Incursions: The Threat On The Ground. Avionics Magazine, 25(4), 16-19.

RTCA Special Committee-186. (2002a). Draft of Airport Surface Situation Awareness Application Description.

RTCA Special Committee-186. (2002b). Draft of Final Approach and Runway Occupancy Awareness Application Description.

Schvaneveldt, R.W., Beringer, D.B., and Lamonica, J.A. (2001). Priority and organization of information accessed by pilots in various phases of flight. International Journal of Aviation Psychology, 11 (3), 253-280.

Yeh, M. and Chandra, D. (2003). Determining Minimal Display Element Requirements for Surface Map Displays. Proceedings of the $12^{\text {th }}$ International Symposium of Aviation Psychology. Wright State University: Dayton, $\mathrm{OH}$. 